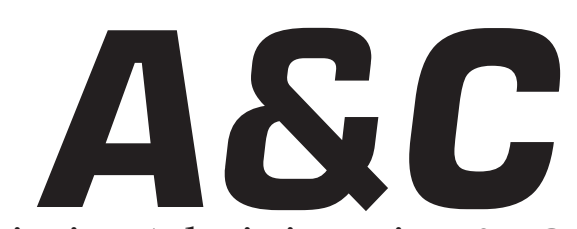

Revista de Direito Administrativo \& Constitucional

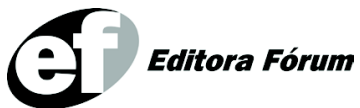

ISSN 1516-3210

A\&C R. de Dir. Administrativo e Constitucional Belo Horizonte ano 8 n. 31 p. 1-272 jan./mar. 2008 


\section{A\&C - REVISTA DE DIREITO ADMINISTRATIVO E CONSTITUCIONAL}

IPDA

Instituto Paranaense

de Direito Administrativo

Direção Geral

Romeu Felipe Bacellar Filho

Direção Editorial

Paulo Roberto Ferreira Motta

Direção Executiva

Emerson Gabardo

Conselho de Redação

Edgar Chiuratto Guimarães

Adriana da Costa Ricardo Schier

Célio Heitor Guimarães

\section{Conselho Editorial}

Adilson Abreu Dallari

Alice Gonzáles Borges

Carlos Ari Sundfeld

Carlos Ayres Britto

Carlos Delpiazzo

Cármen Lúcia Antunes Rocha

Celso Antônio Bandeira de Mello

Clèmerson Merlin Clève

Clóvis Beznos

Enrique Silva Cimma

Eros Roberto Grau

Fabrício Motta

Guilhermo Andrés Muñoz (in memoriam)

Jaime Rodríguez-Arana Muñoz

Jorge Luís Salomoni

José Carlos Abraão
José Eduardo Martins Cardoso
José Luís Said
José Mario Serrate Paz
Juan Pablo Cajarville Peruffo
Juarez Freitas
Julio Rodolfo Comadira
Luís Enrique Chase Plate
Lúcia Valle Figueiredo
Manoel de Oliveira Franco Sobrinho
(in memoriam)
Marçal Justen Filho
Marcelo Figueiredo
Márcio Cammarosano
Maria Cristina Cesar de Oliveira

Nelson Figueiredo

Odilon Borges Junior

Pascual Caiella

Paulo Eduardo Garrido Modesto

Paulo Henrique Blasi

Paulo Neves de Carvalho (in memoriam)

Paulo Ricardo Schier

Pedro Paulo de Almeida Dutra

Regina Maria Macedo Nery Ferrari

Rogério Gesta Leal

Rolando Pantoja Bauzá

Sérgio Ferraz

Valmir Pontes Filho

Yara Stropa

Weida Zancaner

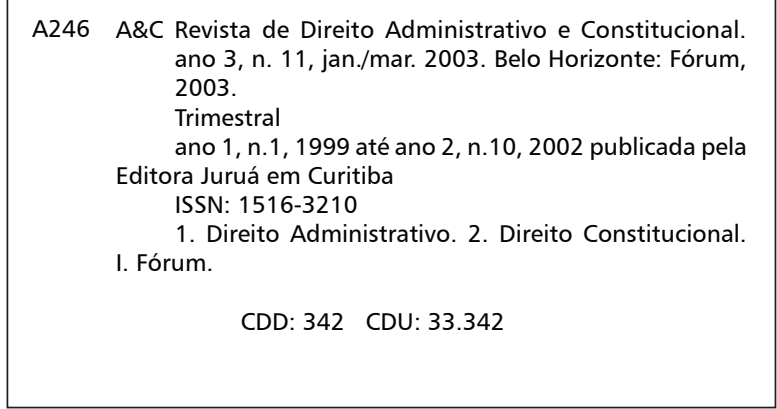

(c) Editora Fórum Ltda. 2008

Todos os direitos reservados. É proibida a reprodução total ou parcial, de qualquer forma ou por qualquer meio eletrônico ou mecânico, inclusive através de processos xerográficos, de fotocópias ou de gravação, sem permissão por escrito do possuidor dos direitos de cópias (Lei $n^{\circ}$ 9.610, de 19.02.1998).

Editora Fórum Ltda.

CEP 30130-007 - Belo Horizonte/MG - Brasil

Tel.: 08007043737

Internet: www.editoraforum.com.br

e-mail: editoraforum@editoraforum.com.br
Av. Afonso Pena, 2770 - 15\%/16 andar - Funcionários

Editor responsável: Luís Cláudio Rodrigues Ferreira

Coordenação editorial: Olga M. A. Sousa

Projeto gráfico e diagramação: Luis Alberto Pimenta

Revisoras: Carolina Rocha

Lourdes Nascimento

Pesquisa jurídica: Fátima Ribeiro - OAB/MG 74868

Bibliotecárias: Fernanda de Paula Moreira

Leila Aparecida Anastácio - CRB 2513 - 6ª região

Os conceitos e opiniões expressas nos trabalhos assinados são de responsabilidade exclusiva de seus autores.

Impressa no Brasil / Printed in Brazil

Distribuída em todo o Território Nacional 


\title{
O devido processo administrativo na execução de termo de ajustamento de conduta
}

\author{
Carlos Ari Sundfeld \\ Professor Doutor da Faculdade e do Programa de Pós-Graduação em Direito da Pontifícia Univer- \\ sidade Católica de São Paulo. Professor da Escola de Direito de São Paulo da Fundação Getúlio \\ Vargas e Coordenador de sua Especialização em Direito Administrativo. Doutor e Mestre em Direito \\ pela PUC/SP. Presidente da Sociedade Brasileira de Direito Público.

\section{Jacintho Arruda Câmara} \\ Professor de Direito Administrativo da Faculdade de Direito da PUC/SP. Mestre e Doutor em Direito \\ pela PUC/SP.
}

Resumo: A Lei da Ação Civil Pública autoriza o Poder Público a produzir, em consenso com o sujeito obrigado, um título executivo extrajudicial: o termo de ajustamento de conduta (TAC). Este estudo chama a atenção para a existência, na fase de execução desse título, de deveres e direitos de índole processual-administrativa, que impõem à autoridade a realização de procedimento administrativo formal para aferir se e como o TAC foi cumprido. Sem isso, não pode ter início a execução judicial do título, para cobrança da multa cominatória.

Palavras-chave: Termo de ajustamento de conduta - TAC. Processo administrativo. Processo legal.

Sumário: 1 Devido processo administrativo na execução de TAC - 2 Direito de acompanhar as diligências administrativas - 3 Direito à intimação para esclarecimentos ou ajustes - 4 Conclusão

\section{Devido processo administrativo na execução de TAC}

O termo de ajustamento de conduta (TAC) é medida para fomentar a adoção espontânea de comportamentos relacionados a interesses difusos ou coletivos, como os dos consumidores. Como alternativa à propositura de ação judicial, a Lei de Ação Civil Pública (Lei no 7.347, de 24 de julho de 1985) prevê a celebração de compromisso entre o órgão público competente e a pessoa interessada, por meio do qual se imponha a esta condições específicas de atendimento às exigências legais, sob pena de uma cominação. ${ }^{1}$

O objetivo da lei é evidente. Trata-se de dotar o órgão público de instrumento consensual que viabilize a pronta adoção, pelo particular, de comportamentos desejados. Privilegiou-se o resultado à busca incerta e

\footnotetext{
A autorização está encartada no art. $5^{\circ}, \S 6^{\circ}$, da Lei n 7.347/85: "Os órgãos públicos legitimados poderão tomar dos interessados compromisso de ajustamento de sua conduta às exigências legais, mediante cominações, que terá eficácia de título executivo extrajudicial".
} 
demorada de sanções na via judicial. A celebração do termo de ajustamento de conduta também é um modo mais rápido para assegurar a aplicação efetiva da norma em discussão. Não se trata de instrumento de punição, mas de indução de comportamentos concretos. O termo constitui uma ferramenta para transformar em realidade abstratas prescrições legais. Quando firma o compromisso, o interessado se vincula a um dado plexo de obrigações, passando o pacto a constituir, por si só, um título executivo, independentemente de ação judicial de caráter constitutivo.

A celebração do TAC, todavia, não esgota o processo de efetivação da norma. Após a definição das obrigações, das condições de seu cumprimento e das cominações aplicáveis, passa-se à fase de implementação. Para os fins jurídico-administrativos, trata-se de parte integrante do processo administrativo em que as obrigações foram constituídas. Por isso, todas as garantias e cuidados processuais terão de ser observados nessa etapa.

\section{Direito de acompanhar as diligências administrativas}

A partir da celebração do termo, o compromissário deve adotar as medidas necessárias ao seu cumprimento, dentro do cronograma pactuado. Simultaneamente, ao órgão público cabe aferir se as obrigações estão sendo devidamente atendidas. Entendendo haver alguma inadequação, é papel do órgão intimar formalmente o compromissário, requisitando os esclarecimentos e determinando a regularização que considere indispensável, sob pena de iniciar-se a fluência da multa cominatória.

O funcionamento deste sistema, por óbvio, sujeita-se à observância de requisitos mínimos, oriundos da garantia ao devido processo legal. Um dos mais importantes envolve a realização de diligências para a apuração do cumprimento do TAC. Como se trata da constituição de elemento de prova, efetuada no curso de processo administrativo, é imprescindível facultar ao interessado (no caso, ao compromissário) a possibilidade de acompanhamento da ação administrativa. A exigência é de suma relevância para a lisura do processo administrativo, posto que, por seu intermédio, assegura-se o direito ao contraditório durante a instrução do processo. O acompanhamento das diligências pelo interessado é, ainda, medida fundamental para conferir eficiência e precisão ao resultado da investigação. Realmente, acompanhado do interessado, o agente fiscalizador terá oportunidade de esclarecer de imediato eventuais dúvidas, evitando equívocos na aferição dos elementos factuais.

Tratando-se de processo administrativo conduzido pela Administração Federal, essa exigência não se fundamenta apenas na aplicação de 
genérico princípio do devido processo legal ou na racionalidade que deve sempre pautar as ações do Estado. No âmbito federal, o dever de realizar diligência com acompanhamento do interessado decorre de disposição expressa de lei. É o que determina a Lei de Processo Administrativo Federal (Lei $\mathrm{n}^{\circ}$ 9.784, de 29 de janeiro de 1999):

Lei de Processo Administrativo Federal

(...)

Art. 41. Os interessados serão intimados de prova ou diligência ordenada, com antecedência mínima de 3 (três) dias úteis, mencionando-se data, hora e local de realização.

Como se vê, a Lei de Processo Administrativo Federal exige a prévia intimação do interessado, propiciando, com isso, condições para que este venha a acompanhar efetivamente a diligência, controlando, apurando e contribuindo para o levantamento de provas que serão empregadas no processo.

Insista-se nisto: a celebração do TAC não encerra o processo que lhe deu causa, apenas resolve consensualmente o tema litigioso, gerando um ato bilateral cuja execução tem de ser feita, impulsionada e controlada no mesmo processo. O processo não se extingue com a simples celebração do TAC porque sua finalidade não está, ainda, exaurida, faltando obter materialmente a conduta desejada do particular. Não é caso de extinção (art. 52, primeira parte, da Lei de Processo Administrativo Federal). Assim, as providências administrativas para aferir o exato cumprimento do termo não são atos avulsos, tampouco mera preparação de futuro e eventual processo sancionatório. Essas medidas administrativas são diligências para produção de prova em processo já constituído - processo esse cujo objeto é, então, a execução do compromisso firmado. Portanto, nenhuma dúvida pode haver quanto à incidência, em relação a elas, do dever instituído pelo art. 41 da Lei de Processo Administrativo Federal. Há processo em curso, há interessados identificados, há instrução probatória a fazer; há, portanto, dever de intimação dos interessados para acompanharem a diligência.

\section{Direito à intimação para esclarecimentos ou ajustes}

No âmbito de um TAC, a diligência serve para que o órgão público possa conhecer formalmente a ação adotada pelo compromissário em atendimento ao pactuado. Constatada a regularidade, a autoridade encerrará o processo administrativo, dando por cumprido o termo. Caso contrário, 
ou seja, se entender que a situação encontrada não é condizente com as obrigações assumidas, deverá intimar o compromissário, indicando qual é, a seu ver, o ajuste a fazer para o pleno cumprimento do pacto ou requisitando o esclarecimento de algum ponto de dúvida. Para tanto, obviamente, será necessário fixar um prazo razoável.

O fundamento legal específico desse dever de intimar para os esclarecimentos ou ajustes do administrado são os arts. 28 e 39, caput, da Lei de Processo Administrativo Federal:

\section{Lei de Processo Administrativo Federal}

\section{(...)}

Art. 28. Devem ser objeto de intimação os atos do processo que resultem para o interessado em imposição de deveres, ônus, sanções ou restrição ao exercício de direitos e atividades e os atos de outra natureza, de seu interesse.

(...)

Art. 39. Quando for necessária a prestação de informações ou apresentação de provas pelos interessados ou terceiros, serão expedidas intimações para esse fim, mencionando-se data, prazo, forma e condições de atendimento.

Ora, se ocorre divergência entre o relatório do administrado e o que a fiscalização constata, é evidentemente necessário que o interessado preste esclarecimentos sobre suas informações anteriores, eventualmente fornecendo a prova do que disse. Para isso, tem a Administração de intimá-lo; é um dever, não uma faculdade (art. 39). De outro lado, se a autoridade firma o entendimento de que remanesce dever a cumprir, de que o interessado ainda não se desincumbiu de seus ônus - ao contrário do que supunha, segundo as informações que tempestivamente prestou -, a Administração tem de comunicá-lo formalmente, para determinar com precisão o comportamento devido e para constituí-lo em mora. Para isso serve a intimação do art. 28; é um dever, não uma faculdade.

Por certo, pode ocorrer divergência entre o particular e a Administração sobre se as obrigações objeto do termo foram ou não cumpridas, e se o foram a contento. $\mathrm{O}$ entendimento, firmado pela fiscalização, de que o relatório apresentado pelo compromissário não espelha fielmente a realidade, ou de que esta não atende às condições do TAC, caracteriza a divergência. Mas não pode a Administração ocultar essa divergência; tem de intimar imediatamente o particular de sua decisão a respeito, para que ele possa ajustar sua conduta ao entendimento administrativo. Afinal,

A \& C R. de Dir. Administrativo \& Constitucional, Belo Horizonte, ano 8, n. 31, p. 90-95, jan./mar. 
como alguém amoldará sua conduta a uma prescrição que desconhece? Eis a razão, portanto, do dever imposto à autoridade pelo art. 28.

Respondida a intimação pelo compromissário, com informações concretas sobre o atendimento de suas obrigações, a autoridade deverá efetuar nova diligência, para atestar sua veracidade ou não. Desta forma, poderá finalmente declarar cumprida a medida (caso a suposta irregularidade tenha sido sanada ou esclarecida) ou, persistindo a inadequação, iniciar a aplicação da multa cominatória, a ser contada a partir da intimação inicial, para forçar a correção da conduta considerada incorreta.

É importante ressaltar mais um aspecto quanto à necessidade de prévia e imediata intimação do compromissário, na hipótese de a fiscalização entender existente alguma irregularidade ou inadequação na implementação do termo. Como foi visto, a celebração do TAC tem por objetivo primordial a rápida adoção de conduta de interesse difuso ou coletivo. Se houver qualquer inadequação entre as medidas adotadas por quem assumiu o compromisso e as previsões do ajuste, torna-se fundamental que o órgão competente o intime imediatamente para que, de fato, as providências exigidas na legislação venham a ser adotadas. Sem isso, o compromissário não saberá de sua situação de inadimplência, prorrogando, assim, o período em que a norma permanecerá desatendida e comprometendo a razão de ser do compromisso, que é a solução rápida e efetiva da pendência.

O objetivo da intimação é, portanto, também permitir que, em tempo hábil, sejam corrigidas eventuais irregularidades remanescentes. A intimação, tanto quanto a própria celebração do termo, busca efetivar as normas de proteção aos interesses difusos ou coletivos previstas na legislação.

Somente após o vencimento do prazo para realizar as adequações ou esclarecimentos, persistindo, na visão da autoridade, a desconformidade, caberá a fluência das cominações previstas no termo. Apenas nesse momento a imposição da multa cominatória alcançará o sentido que a lei lhe outorgou, isto é, induzirá o compromissário a atender às exigências contidas no pacto, cujos contornos fáticos já terão sido objeto de regular determinação.

De fato, com a intimação informando que, no entender da autoridade, as providências tomadas ainda se mostram insuficientes para dar fiel cumprimento ao TAC, o compromissário terá prazo para adequar suas medidas ou prestar os esclarecimentos necessários. Se, mesmo após a intimação, não forem tomadas as providências necessárias, será cabível a 
aplicação das multas de natureza cominatória. Nesse momento, sabendo o teor da irregularidade apontada, o compromissário haverá de buscar sua correção no período mais breve possível, para que sua multa não seja multiplicada.

Por outro lado, sem intimar o compromissário a respeito das irregularidades encontradas, a multa cominatória deixaria de atender ao seu fim legal. Deveras, desconhecendo a suposta irregularidade, o compromissário não teria como regularizar a situação. A incidência da multa seria informada ao infrator apenas no momento de sua cobrança o que, de fato, não funcionaria como instrumento de indução ao célere cumprimento das obrigações.

O silêncio da Administração credora, a ausência de recusa formal da prestação realizada pelo particular — e objeto das informações por ele prestadas - impede a mora. Sem a intimação do particular, que configuraria a recusa, não há mora, nem pode fluir multa cominatória.

\section{Conclusão}

Tendo em vista o exposto, a aferição de cumprimento de um TAC deve atender aos seguintes passos: a) intimação prévia do compromissário, informando-lhe as circunstâncias em que será realizada a diligência; b) intimação formal das irregularidades encontradas, com a estipulação de prazo razoável para que o compromissário possa esclarecê-las ou saná-las; c) realização de nova diligência para verificar se houve regularização; e d) fluência da multa cominatória, caso não seja efetuada a regularização ou o esclarecimento.

O ingresso do Poder Público em juízo, para cobrança da multa cominatória, não pode ocorrer sem a prévia e regular realização do procedimento administrativo, com os passos mencionados.

Informação bibliográfica deste texto, conforme a NBR 6023:2002 da Associação Brasileira de Normas Técnicas (ABNT):

SUNDFELD, Carlos Ari; CÂMARA, Jacintho Arruda. O devido processo administrativo na execução de termo de ajustamento de conduta. A\&C Revista de Direito Administrativo e Constitucional, Belo Horizonte, ano 8, n. 31, p. 90-95, jan./mar. 2008. 